\title{
Composite Indicators to Measure Quality of Working Life in Europe: A Systematic Review
}

\author{
Elena Stefana ${ }^{1}$ (D) - Filippo Marciano ${ }^{1}$ (D) - Diana Rossi ${ }^{1}$ (D) Paola Cocca $^{1}$ (D) . \\ Giuseppe Tomasoni ${ }^{1}$ D
}

Accepted: 15 April 2021 / Published online: 23 April 2021

(c) The Author(s) 2021

\begin{abstract}
In the last two decades, Quality of Working Life (QWL) has become a core element of the European social model and the European Employment Strategy. "More and better jobs" is a strategic goal promoted within Europe for emphasising the attention in QWL. However, there is a large debate in the literature on the definition of QWL, its dimensions, and consequently on the methods to use for its measurement. To the best of our knowledge, the systematic reviews currently available in the literature on QWL measurement in European organisations investigate only a particular industry and/or working population. Moreover, they do not focus specifically on composite indicators, although they appear promising in facilitating QWL understanding and comparisons for supporting decision-makers and policy makers. To overcome these gaps, we conducted a systematic review to identify composite indicators for measuring QWL in European organisations. The review returned 19 studies that are analysed based on a set of factors related to QWL locutions, index name, geographical area, industry or population, level of analysis, dimensions, type of data, inputs, outputs, and test and/or validation. The results highlight a significant heterogeneity among the indicators, confirming the lack of an agreed upon QWL composite indicator for Europe. Such heterogeneity concerns also QWL dimensions. A critical comparison of the different composite indicators is provided, along with a unifying proposal of QWL macrodimensions. Several gaps in the literature are pointed out suggesting directions for future research.
\end{abstract}

Keywords Job quality · Good job · Decent work · Employment · European Union · Composite indicator

\section{Introduction}

Quality of Working Life (QWL) has become subject of growing interest within the economic, social, sociological, and psychological research (Boccuzzo \& Gianecchini, 2015; Díaz-Chao et al., 2016; Simões et al., 2015). An enhancement in QWL can bring benefits

Elena Stefana

elena.stefana@unibs.it

Extended author information available on the last page of the article 
to workers and companies, improving working conditions, fostering workers' health and well-being, increasing work motivation, developing workers' skills, promoting sustainable work, growing productivity and competitiveness, and reducing unemployment (e.g. DíazChao et al., 2017; Muñoz de Bustillo et al., 2009, 2011a; Santero-Sanchez et al., 2015; Šverko \& Galić, 2014).

The literature has not reached a general agreement neither on a comprehensive QWL definition, nor on its measurement (e.g. Bäck-Wiklund et al., 2011; Barroso, 2018; Hurley et al., 2012; Jones et al., 2017; Leschke \& Watt, 2014; Muñoz de Bustillo et al., 2011b; Schokkaert et al., 2011). QWL measurement is currently performed through a wide variety of indicators and methods (e.g. Boccuzzo \& Gianecchini, 2015; Crespo et al., 2017; Muñoz de Bustillo et al., 2009). Some reviews investigating QWL measurements in a specific work sector or geographical area and/or focusing on a particular scientific database are available in the literature. For example, Muñoz de Bustillo et al. (2011b) provide a critical survey of 19 job quality indicators or systems of indicators developed for different scopes or contexts (e.g. European Union, developed and developing countries, USA). Phan and Vo (2016) analyse studies about specific tools and scales to assess QWL in medical organisations. Barroso (2018) has recently performed a methodological review of the most-cited articles indexed in the Scopus database to assess progress in the harmonisation of QWL concepts and measurement. However, these reviews do not focus specifically on composite indicators as a possible methodology for QWL measurement, although such approach appears particularly effective. A composite indicator for QWL measurement is "a single aggregate measure synthesizing the information of all the different attributes of job quality" (Muñoz de Bustillo et al., 2011b), and "the mathematical combination of individual indicators, each of which is related to a particular dimension of the phenomena to be analysed" (Santero-Sanchez et al., 2015). A composite indicator allows a univocal and unidirectional understanding of what QWL is, positioning and ranking the studied subjects or groups within a one-dimensional axis going from bad to good, as underlined by Muñoz de Bustillo et al. (2011b). The interest in composite indicators is largely acknowledged, since they are useful to: summarise complex or multi-dimensional issues for supporting decision-makers; enable users to compare complex dimensions effectively; reduce the size of a list of indicators; plan targets and control their achievement; attract public interest; and provide a transparent way for policy makers and public opinion (e.g. OECD and JRC European Commission, 2008; Saltelli, 2006; Tangian, 2005). Composite indicators have gained astounding popularity in all research areas, and can reflect a complex system consisting of numerous components, making it easier to understand in full rather than reducing it back to its spare parts (Greco et al., 2019).

Based on these arguments, the aim of this article is to carry out a systematic review to identify the composite indicators available in the literature for measuring QWL at the individual worker, job, or company level.

We decided to narrow the scope of our analysis to European organisations. Although the sense of a good job, working conditions, and rights could be slightly different across countries (Burgess \& Connell, 2008; Sojka, 2014), through the Community Charter of the Fundamental Social Rights of Workers adopted in 1989 all the European Member States have committed to establish a shared social policy and shape the development of the European social model, thus fostering a common understanding also of QWL concept. In the last two decades, QWL has become a core element of the European social model and the European Employment Strategy (e.g. Bothfeld \& Leschke, 2012; Dahl et al., 2009; PenaCasas, 2009; Smith et al., 2008). Indeed, a strategic pillar of the European Employment Strategy and the Lisbon Strategy has been to promote more and better jobs within Europe 
(European Commission 2001b), and the improvement of working conditions and job quality continues to be a significant goal in European policies, underpinning Europe's capacity to compete (Eurofound, 2017).

The results of our review will allow: (1) summarising the state of the art of the scientific literature concerning the various composite indicators for measuring QWL; (2) identifying similarities and differences among the several approaches; (3) comparing them for supporting the selection of the most suitable composite indicator for the QWL measurement in a specific European organisation; and (4) revealing possible gaps in the literature that should be addressed thanks to future research for reaching a consensual QWL measure.

\section{Theoretical Background}

The first important attempts to define QWL were by both Boisvert and Morton in 1977. The former states that QWL is a "set of beneficial consequences of working life for the individual, the organization and society" (Boisvert, 1977), while the latter refers to this concept as "every conceivable aspect of the work ethic and working conditions", including objective measures of working conditions, workers' expressions of satisfaction and dissatisfaction, and broader considerations of social cohesion and stability (Morton, 1977). Over the decades, several researches have emphasised different elements of this topic: according to Efraty and Sirgy (1990), and Sirgy et al. (2001), QWL is a conceptualisation related to satisfaction of various needs, whereas recently it has been linked to workers' own evaluations of job (Burchell et al., 2014) and individuals' subjective perception of their jobs (Santero-Sanchez et al., 2015).

Besides QWL, a plethora of related terms are used in the literature: "job quality", "employment quality", "quality of work", "quality in work", "good job", "quality of life at work", or "decent work".

Job quality is related to the set of work-and employment-related factors that have a positive and direct effect on the worker's well-being (Boccuzzo \& Gianecchini, 2015). According to Eurofound (2012), it is the utility that a worker derives from his/her job, depending on job features (according to the subjective tradition), and is constituted by the job features and attributes that meet workers' needs from work (in the objective tradition). All these aspects are well summarised by Díaz-Chao et al. (2016, 2017), and Ficapal-Cusí et al. (2018), who describe job quality as an overall state of satisfaction that includes objective aspects of material well-being, satisfactory relationships with the physical and social environment, and objectively perceived health; and subjective aspects of physical, psychological and social well-being. Muñoz de Bustillo et al. (2009, 2011b) consider job quality as a set of employment quality and work quality. The former indicates all the elements potentially affecting workers' well-being related to the employment relation (e.g. type of contract, working hours, distribution of working hours, wage, social benefits), while the latter the ways that the activity of work itself and the conditions under which it is undertaken can affect the well-being of workers (e.g. work autonomy, physical working conditions, risk of accidents, social working environment). Steffgen et al. (2015) agree with these definitions, highlighting that quality of work is a concept that bridges the gap between job quality and employment quality. Other authors (Burchell et al., 2014; Santero-Sanchez et al., 2015) quote the terms "job quality" and "quality of work", referring as a concept focusing on the (objective) job content and work environment. 
European Commission (2001a) defines quality in work (better jobs) as a relative and multi-dimensional concept taking into account objective characteristics of employment, worker characteristics, the match between worker characteristics and job requirements, and the subjective evaluation (job satisfaction) of these characteristics by the individual worker. Job satisfaction is contained also in the good job definition provided by Bang and Lee (2006): a good job is a concept related to wages as an economic compensation, to job status as a social status, and to job satisfaction as a subjective psychological criterion.

Job satisfaction can be characterised as "a global feeling about the job or as a related constellation of attitudes about various aspects or facets of the job" (Spector, 1997). Although some researchers (e.g. Diaz-Serrano \& Vieira, 2005; Hurley et al., 2012; Simões et al., 2015) propose job satisfaction as a possible proxy of QWL, it is one of many possible outcomes of QWL not sufficient by itself for its complete description, and thus QWL is considered a much broader concept than job satisfaction (Carpita \& Golia, 2012; Lawler, 1975; Sirgy et al., 2001; Sojka, 2014).

Another locution frequently mentioned in the literature related to QWL is "decent work", which refers to the converging focus of all the four strategic objectives of the International Labour Organization (ILO): promotion of rights at work, employment, social protection, and social dialogue (ILO, 1999). Ferraro et al. (2018) describe it as a concept created for promoting economic and social human development in the formal and informal economy. In other words, decent work is related to meaningful work and ethics that ensure fundamental values and principles at work through social dialogue among those involved in the decision-making processes regarding that work (Ferraro et al., 2017). The European Foundation for the Improvement of Living and Working Conditions (Eurofound) states that the decent work concept is similar in spirit but broader in the scope of needs that it addresses than job quality (Eurofound, 2012).

The above concise overview highlights the several differences and overlaps among all the QWL-related terms, which are often used interchangeably and indistinctively. For instance, Burchell et al. (2014) point out that expressions such as "quality of working life", "job quality", "quality of job", "quality of employment", and "decent work" are often used interchangeably and without clear definitions; Steffgen et al. (2015) remark that the terms "job quality", "quality of job", and "employment quality" are often used interchangeably, and clearly defining them remains a challenge; and Barroso (2018) states that the concept of "quality of work" is often used indistinctively from notions of "quality of working life" or "job quality".

The difficulties related to a shared QWL definition arise mainly from its multidimensional nature (Schnalzenberger et al., 2014; Schokkaert et al., 2011). This multidimensional nature should be captured by any indicator for the QWL measurement: the various dimensions affecting the work and employment should be defined, considered, and aggregated based on their impact on QWL (Muñoz de Bustillo et al., 2009, 2011a). Therefore, QWL should be evaluated by means of a multidimensional approach by using a combination of objective and subjective data and information (Díaz-Chao et al., 2016, 2017; Hurley et al., 2012). Indeed, two perspectives can be identified in the literature: (1) an objective one, linked to working environment characteristics and objective features of the job, such as security, ergonomics, technology, management systems, organisation processes, and salary, and (2) a subjective one, relating to employee work preferences and their perceived fulfilment, e.g. satisfaction, attitudes, motivation, commitment, and pride (Díaz-Chao et al., 2016; Holman, 2013). As a consequence, the QWL measurement methods can adopt an objectivist approach, a subjectivist approach, or a multi-faceted approach. Multi-faceted 
approaches represent a mix of the two, including both objective facets of the job and subjective perceptions of the worker (Boccuzzo \& Gianecchini, 2015).

In addition, a combination of dynamic and static interpretations should be adopted (Díaz-Chao et al., 2016, 2017), since the dimensions and conditions establishing QWL may change and evolve over time, varying across locations, countries, organisations, and industries, and among individuals, in terms of preferences and priorities (Burgess \& Connell, 2008; Jones et al., 2017; Sojka, 2014). In particular, individuals' evaluations of job quality evolve over time, as an individual's work experience at any one time determines his/her expectations about future work activities and affect his/her work-related behaviours (Boccuzzo \& Gianecchini, 2015).

Consequently, the required wide-ranging data and information, the numerous sets of possible dimensions, and the actual multidimensional nature of QWL make the definition of a QWL indicator a debated topic (Muñoz de Bustillo et al., 2009, 2011a).

To capture all these concepts in their broadest sense, we refer mainly to "quality of working life" locution in this paper, using all the previous locutions (with the exception of job satisfaction) as synonyms in our literature selection and review. We consider "working life" as the employees' experience of working conditions and work-life balancing issues that can impact their lives. Consequently, QWL is the set of characteristics of work, characteristics of working and non-working life balance, and employees' evaluation of these characteristics. Our aim is to obtain the widest spectrum of composite indicators for measuring QWL, including both objectivist and subjectivist approaches, both static and dynamic interpretations, in order to characterise the state of the art of the literature and correlate the several existing locutions with the main features and dimensions of the different composite indicators. Indeed, the provision of a comprehensive overview could allow researchers and practitioners to select the indicator that best suits their needs and/or give them useful information to build a new indicator.

\section{Methods}

A systematic review allows identifying key scientific contributions to a field, and exploring a clearly specified question (Denyer \& Tranfield, 2009; Tranfield et al., 2003). Since our systematic review fits the management and organisation studies, we conducted it according to the principles and guidelines defined by Briner and Denyer (2012), Denyer and Tranfield (2009), Denyer et al. (2008), and Tranfield et al. (2003), following the steps shown in Fig. 1 and described in the next paragraphs.

\subsection{Research Question and Eligibility Criteria}

The systematic review begins with the research question formulation to establish its focus. Our research question is: "Which composite indicators can be used to measure QWL in European organisations?". For our review, we adopted the framework based on CIMO logic and concepts (Denyer et al., 2008). In particular, the CIMO keywords have been defined as follows:

- Context (C): Europe;

- Interventions (I): QWL;

- Mechanisms (M): not present in this review; 




Research question and eligibility criteria

Locating studies

Study selection

Analysis of retrieved studies

Fig. 1 Search strategy and analysis of the selected studies

- Outcome $(\mathrm{O})$ : indicator.

To capture all relevant studies and produce a comprehensive review, we defined a set of synonyms and related terms for each CIMO keyword thanks to the conduction of scoping studies. We expressed the Context concept through nouns and adjectives of Europe (politico-economic union), European regions and/or countries: we did not specify more detailed geographical areas (e.g. cities or districts). The defined synonyms are listed in Table 1.

The relevance of each study to the research question was assessed based on the inclusion (or eligibility) and exclusion criteria listed in Table 2.

\subsection{Locating Studies}

By means of synonyms and related terms of each CIMO keyword, Boolean operators, and simple operators (e.g. truncation characters), we constructed several search strings to adhere to the different search conventions of each database. The following key databases within the field of management were searched, considering studies published before 31 







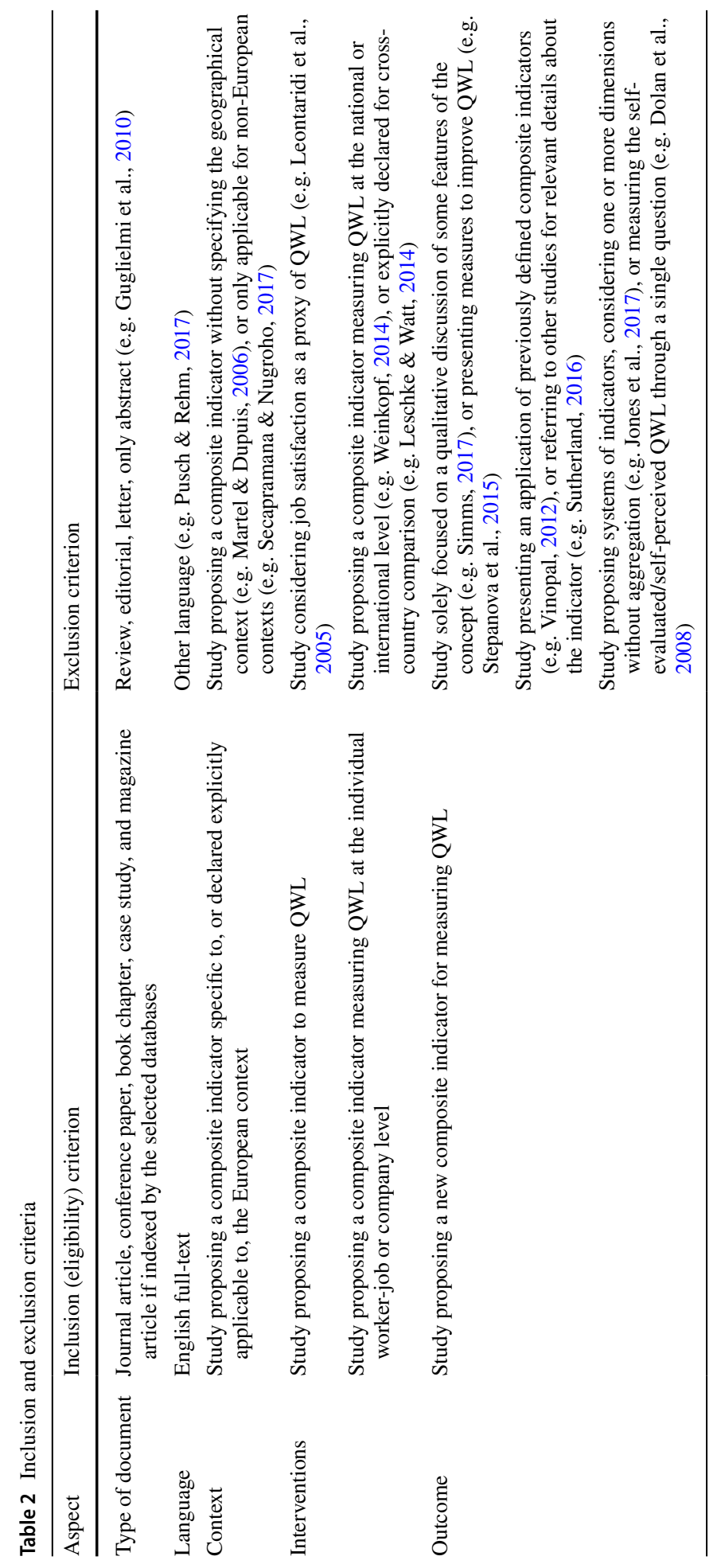


July 2018: EBSCO (all databases, scholarly journals), EMBASE, Emerald, PubMed, Scopus, and Web of Science. A starting date was not defined in order not to exclude potentially relevant papers and to extend the search from the date of the oldest indexed paper of each database.

Scoping studies help to assess the relevance and size of the literature and to delimit the subject area or topic (Tranfield et al., 2003). Based on the outcomes of preliminary scoping studies, we searched for keywords and synonyms of the Context and Interventions concepts only in title, abstract, and keywords fields. On the contrary, terms related to the Outcome concept were searched in all the available fields to maximise the results provided by bibliographic databases.

We employed Endnote ${ }^{\circledR}$ X9 as a reference management software for recording references, storing information accurately, removing multiple records, and creating a unique database of references. The subsequent manual removal of other duplicates allowed obtaining a unique library representing our initial database.

\subsection{Study Selection}

We performed the study selection through a screening process in a Microsoft ${ }^{\circledR}$ Excel spreadsheet created from the initial database. The screening process consisted of three stages (Stefana et al., 2015): (1) title evaluation, (2) abstract and keywords evaluation, and (3) full-text evaluation. In each stage, three reviewers critically appraised the records in parallel; all the documents selected by at least one reviewer have been promoted to the successive screening stage to minimise the chance to discard relevant papers.

In particular, irrelevant studies were removed during screening stages (1) and (2), as established by Higgins and Green (2008). For example, we discarded the studies related to the quality of products or tasks performed by workers, and documents identified as reviews or editorials.

During the last screening stage, we examined the full-texts of the remaining documents based on all the eligibility criteria listed in Table 2. As a consequence, we collected the included documents in the final database (i.e. the documents that answer the research question), and recorded the primary reason for exclusion of the other papers.

The intermediate and final results of the study selection process are summarised in Fig. 2, as recommended by Moher et al. (2009).

Finally, we characterised and analysed the documents included in the final database. These documents provide the answer to the research question, whose main features are described in detail in the following sections.

\section{Results}

The systematic review returned 19 documents, each one proposing a different composite indicator to assess QWL. The majority are journal articles (13 out of 19), a few book chapters (5 out of 19) (Clark, 2005; McClelland \& Holman, 2015; Muñoz de Bustillo et al., 2011a; Paugam \& Zhou, 2008; Ventegodt et al., 2009), and only one is a conference paper (Addabbo et al., 2007). The journal that published the highest number of papers is "Social Indicators Research" with 3 papers, followed by "Work, Employment and Society" with 


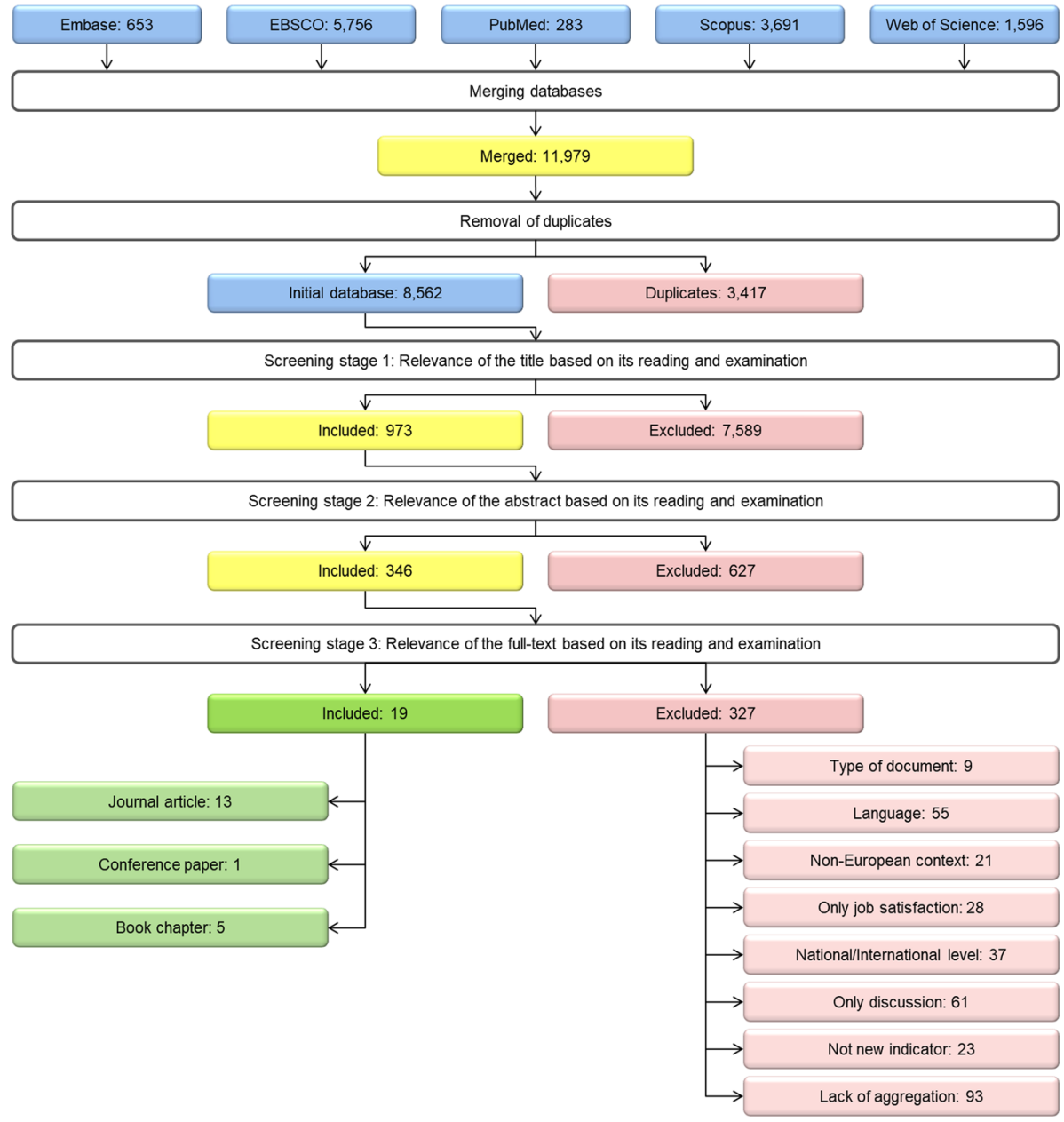

Fig. 2 Flowchart of the systematic review

2 papers. The most recent papers (i.e. Arranz et al., 2018; Warren \& Lyonette, 2018) are published in these two journals.

In order to analyse the documents of the final database, we identified a set of factors useful to highlight the distinguishing features of the proposed composite indicators: (1) terms and locutions used for describing the QWL concept; (2) name of the index; (3) geographical area in which the study is carried out; (4) industrial sector or population for which the composite indicator is developed; (5) level of analysis of the QWL composite indicator (individual worker-job/company), (6) QWL dimensions considered by the composite indicator; (7) type of data employed for the study (primary/secondary); (8) type of inputs of the composite indicator (subjective/objective); (9) type of composite indicator outputs (qualitative/quantitative); and (10) composite indicator test and/or validation. Table 3 shows the characterisation and comparison of the 19 documents with respect to such factors. 


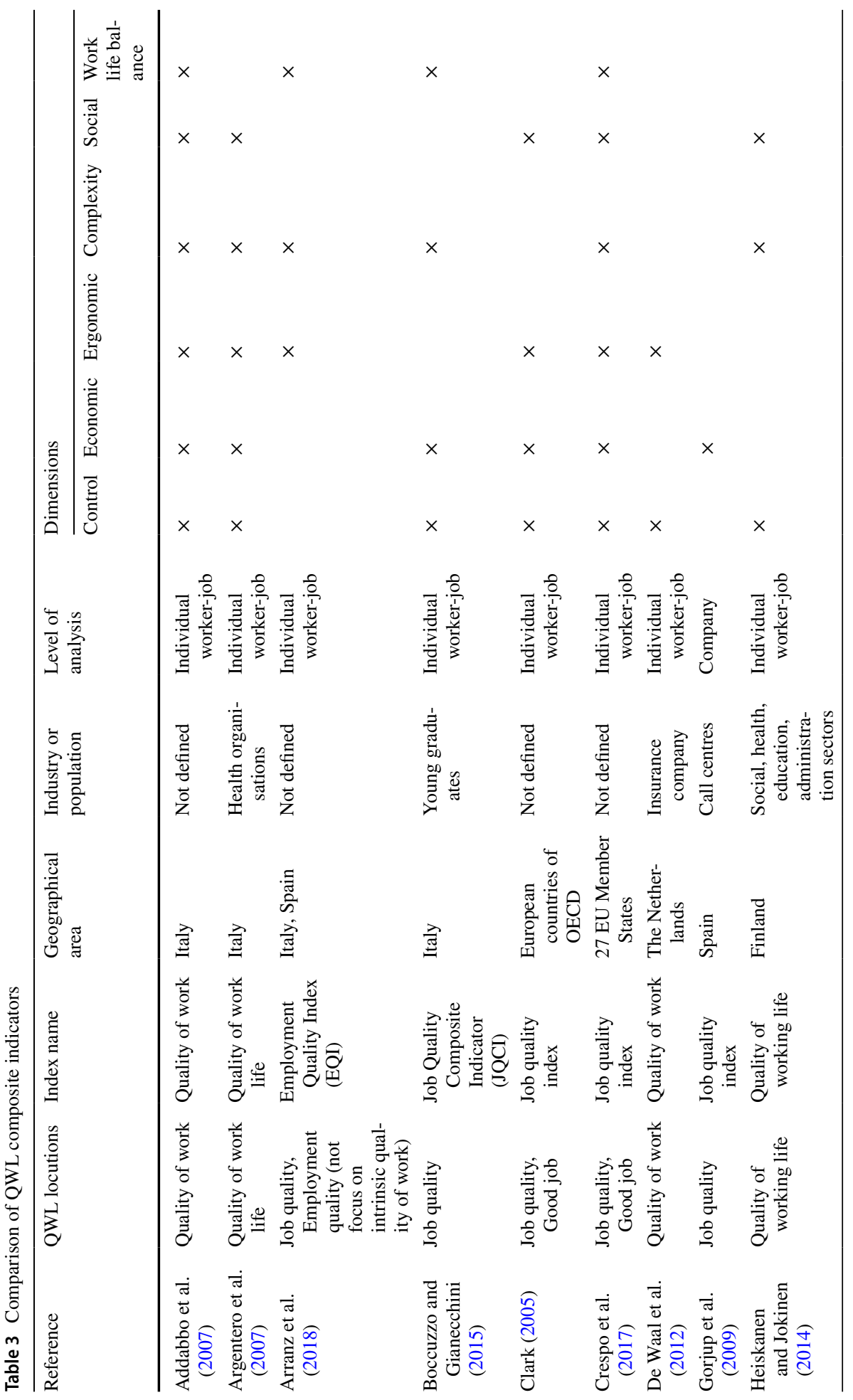




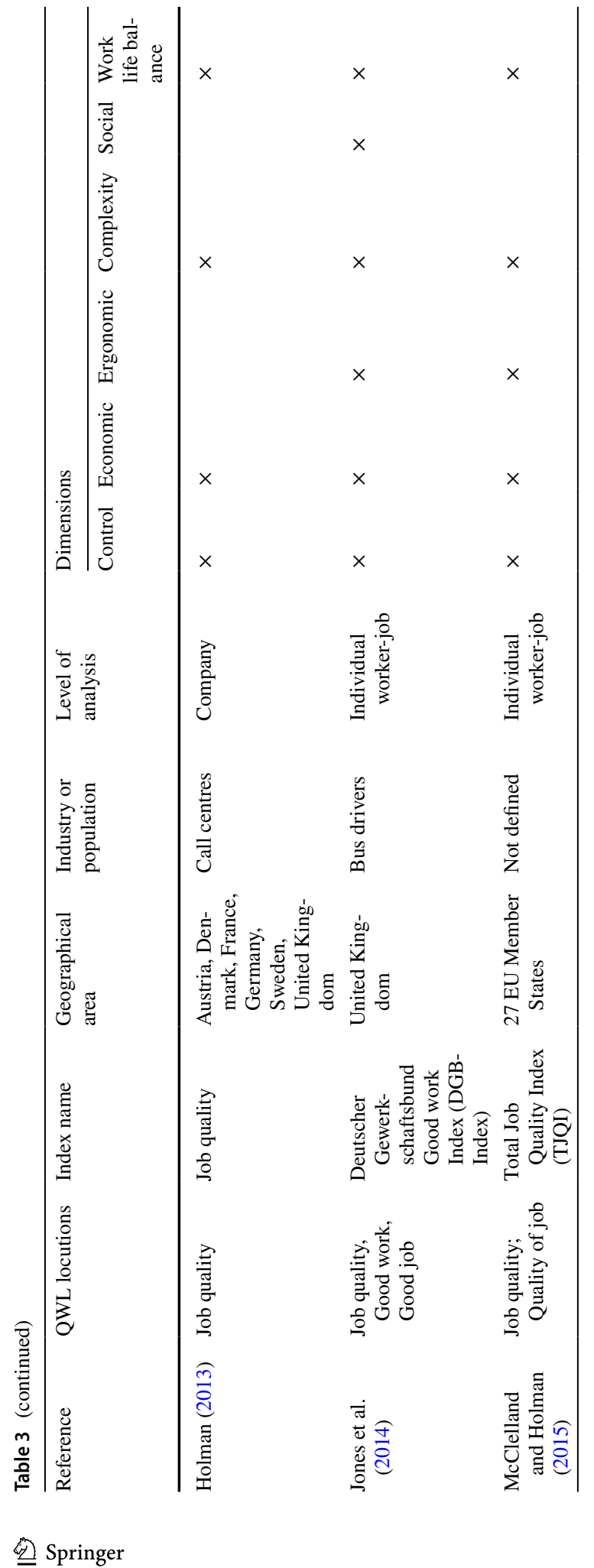









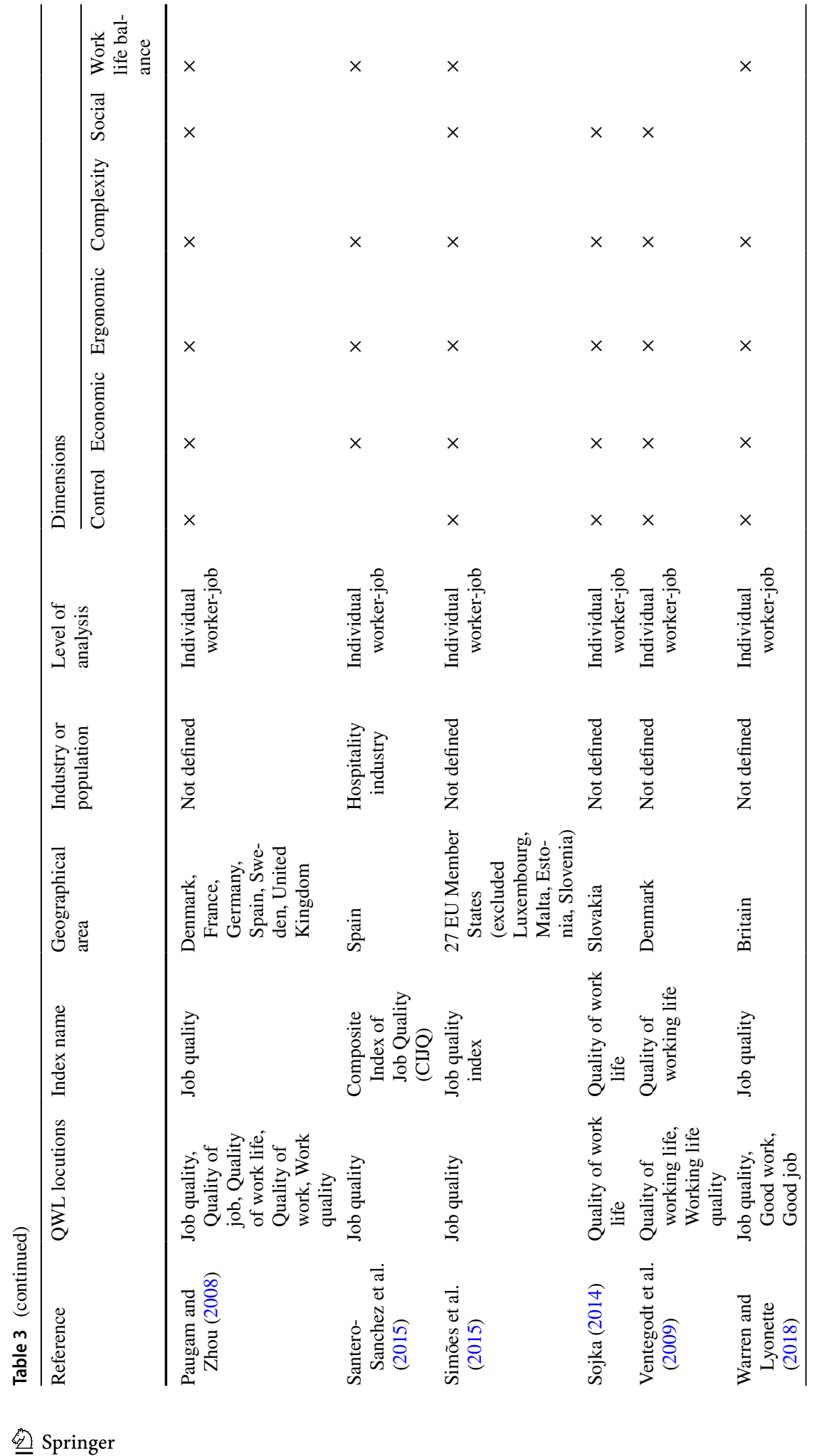




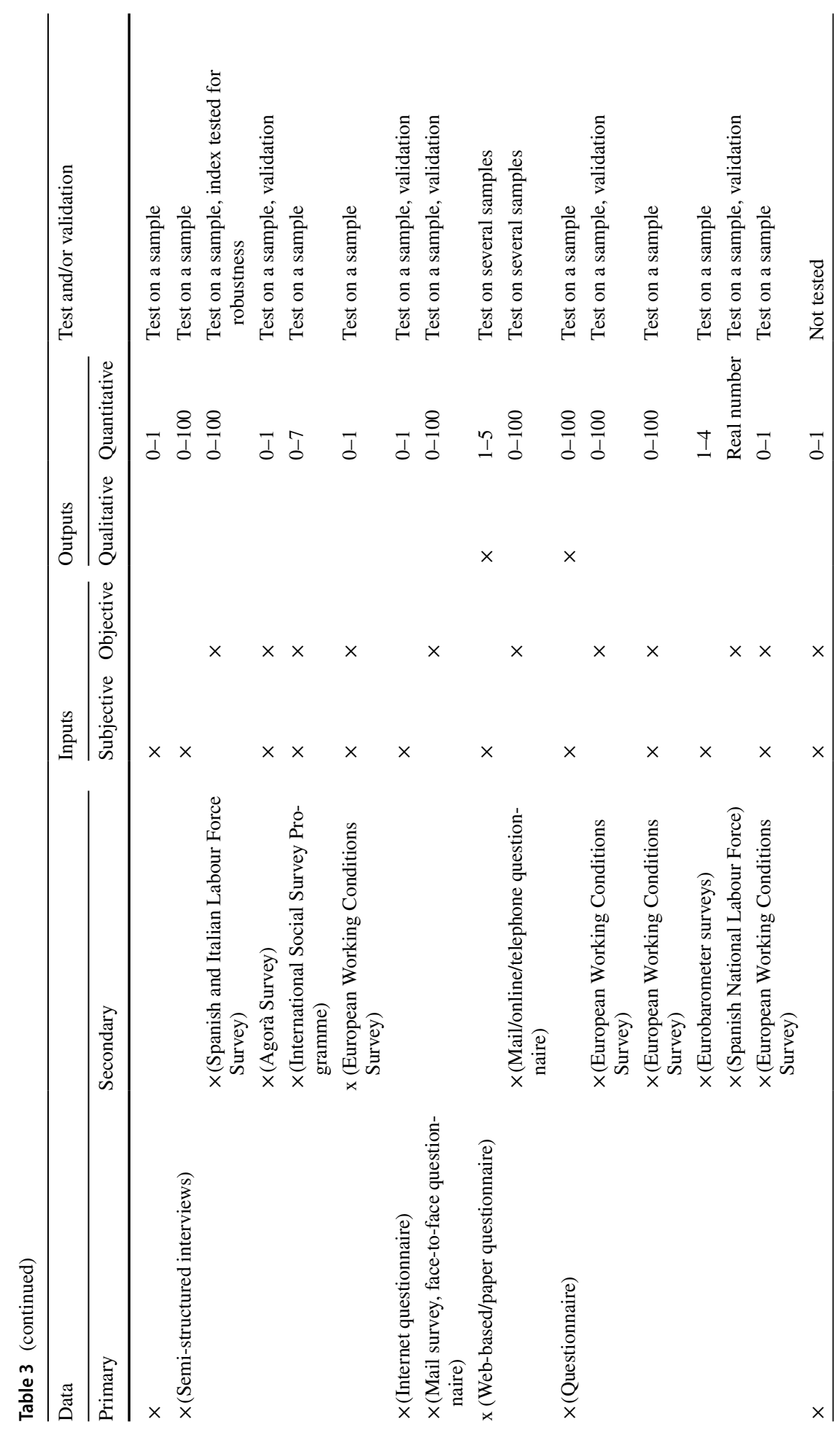




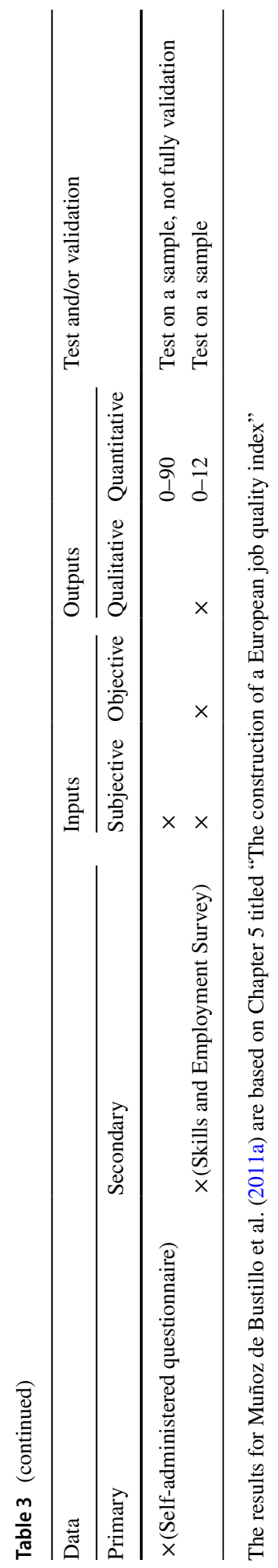

Springer 


\subsection{Terms and Locutions for the QWL Concept, and Index Name}

More than ten phrases are used to express the QWL concept. The majority of the studies (10 out of 19) refer to "job quality" and/or locutions composed by "quality" and "job", while 7 papers use "quality" and "work" terms. The other studies adopt various locutions, e.g. employment quality and good job/work. None paper refers to "decent work", probably because the papers using such wording usually aim to inform policy makers and focus on comparisons among countries using also data on the labour market, which cannot be referred to the individual worker/job or company level. The name of the index usually coincides with the locution used to express the QWL concept. Only three papers make explicit the multidimensional nature of the index including in the name terms such as "composite" (Boccuzzo \& Gianecchini, 2015; Santero-Sanchez et al., 2015) or "total" (McClelland \& Holman, 2015).

\subsection{Geographical Area, Industry or Population, and Level of Analysis}

The majority of the documents (11 out of 19) focus on only one European country. Three papers are concentrated only on Italy, but on different populations. Specifically, Argentero et al. (2007) concentrate the attention on health workers in seven different operating units, Boccuzzo and Gianecchini (2015) analyse young graduates, and Addabbo et al. (2007) test their model through a sample of employees working in firms of different sizes and belonging to different industries. Two articles consider only Spain: Gorjup et al. (2009) examine call centre workers, and Santero-Sanchez et al. (2015) pay attention to hospitality industry. Two studies are carried out in the United Kingdom: Jones et al. (2014) investigate bus drivers, while Warren and Lyonette (2018) women workers in part-time jobs in Britain. One document (Ventegodt et al. 2009) concentrates on Denmark, whereas another (Heiskanen \& Jokinen, 2014) on Finnish municipalities. Lastly, De Waal et al. (2012) examine workflow management system end users in a social insurance company in the Netherlands, while Sojka (2014) studies QWL in Slovakia.

Other documents propose QWL composite indicators applied in multiple countries. For instance, Arranz et al. (2018) provide an index that serves to measure employment quality both in Spain and in Italy. Holman (2013) focuses on call centre agents in Austria, Denmark, France, Germany, Sweden, and UK, whereas Paugam and Zhou (2008) on industry, and retail and hotels in Denmark, France, Germany, Spain, Sweden, and UK. The remaining five documents (i.e. Clark, 2005; Crespo et al., 2017; McClelland \& Holman, 2015; Muñoz de Bustillo et al., 2011a; Simões et al., 2015) refer to a larger set of European countries.

In terms of the level of analysis, only two composite indicators are calculated at the company level (Gorjup et al., 2009; Holman, 2013). Both of them focus on call centres. All the other QWL composite indicators are intended to assess the individual worker or job, and can usually be aggregated to compare types of work, group of workers, or labour markets. For example, Arranz et al. (2018) aggregate individual values of their employment quality index to compare workers that hold an open-ended contract, with workers with temporary contracts hired directly by companies, and those working through a temporary help agency across different countries. McClelland and Holman (2015) consider job quality of vulnerable workers in growing and declining sectors of the European economy by aggregating their Total Job Quality Index by gender, age, and sector for comparison. 


\subsection{QWL Dimensions}

Our review confirms that the number of dimensions considered to calculate QWL is highly variable, ranging from 2 (De Waal et al., 2012) to 22 (Ventegodt et al., 2009). In addition, the different authors refer to dimensions by means of various names, such as dimensions, variables, or components. A list of the dimensions considered in each document is presented in Table 4 located in Appendix. To enable a comparison of the proposed composite indicators we decided to classify the dimensions considered by each indicator into six macro-categories, namely: control, economic, ergonomic, complexity, social, and work life balance. These categories, adapted from the proposals by Addabbo et al. (2007) and McClelland and Holman (2015), have been selected since they appear to be able to accommodate the miscellaneous dimensions included in the 19 QWL composite indicators identified in the literature.

The "control" dimension refers to the degree of freedom or discretion the worker has within his/her job, for example in terms of autonomy in managing working rhythms, possibility of direct agreement with colleagues and management/entrepreneur. We include in this dimension also the features of jobs that allow workers to speak up about work-related issues of importance to them, in terms of representation and voice.

In the "economic" dimension we consider the remuneration of the job and its security, for example in terms of earnings, seniority, job security, social insurance, profit sharing, wage, career perspectives, and protection.

The "ergonomic" dimension refers to working conditions and environment, for example in terms of work environment (e.g. individual space, smokes and fumes, dust), pace and intensity, cognitive effort, and stress.

The "complexity" dimension assesses the requirement for workers to use or develop skills within their job, for instance in terms of acknowledgment of one's capabilities, job variety and richness, effort required, and training.

The "social" dimension deals with the quality of workers' relationships with colleagues, management/entrepreneur, and subordinates, considering also elements connected to others' esteem, acknowledgment of professional abilities, sharing firm's decision, work life satisfaction, and job satisfaction.

The "work life balance" dimension considers the possibility for the workers to balance their work and life commitments, for instance in terms of maternity protection, parental leaves, management and availability of paid holidays, participation of employees in management of working hours distribution and shifts, and availability of family-friendly policies.

The results show that the dimensions considered by the majority (84\%) of the QWL composite indicators are "control", "economic", and "complexity". The less considered are "social" and "work life balance", respectively in 11 and 12 indicators out of 19. Only 6 composite indicators integrate all QWL dimensions, while 4 indicators focus only on 3 dimensions or less.

\subsection{Data, Inputs, Outputs, and Test and/or Validation}

One of the main differences among the QWL composite indicators proposed in the literature concerns the data used for their calculation. In 8 cases out of 19 the study relies on primary data (i.e. data specifically gathered for the purpose of that study), whereas in the remaining 11 cases on secondary data (i.e. data collected for other purposes and then 
reused). Unfortunately, only for half of the studies collecting primary data the full set of questions/items used is provided (De Waal et al., 2012; Gorjup et al., 2009; Heiskanen \& Jokinen, 2014; Ventegodt et al., 2009). The main source of secondary data appears to be the European Working Condition Survey (EWCS), which is used in 4 cases. Three of them also specify the questions of the EWCS providing the data necessary for calculating the composite indicator (Crespo et al., 2017; Muñoz de Bustillo et al., 2011a; Simões et al., 2015). The EWCS has been run every five years since 1990 in European countries surveying a random sample of workers, both employees and self-employed. Other sources of secondary data are national labour force surveys (e.g. Arranz et al., 2018; Santero-Sanchez et al., 2015; Warren \& Lyonette, 2018), European surveys (e.g. Paugam \& Zhou, 2008), and the International Social Survey Programme (Clark, 2005).

The three approaches traditionally employed in QWL measurement (i.e. subjectivist, objectivist, multi-faceted) are well represented in the results of our review. Indeed, the majority of QWL composite indicators adopt either a subjectivist (7 out of 19) or multifaceted approach (7 out of 19), while only 5 a purely objectivist one. The composite indicators adopting a purely objectivist approach mainly use "job quality" locution. Furthermore, it emerges that all the indicators that consider the "social" dimension need to rely on subjective inputs. Indeed, it would be difficult to assess the quality of workers' relationships through objective data. The documents focusing on "work" or "working life" are always subjectivist or multi-faceted, while those focusing on "job" or "employment" are always objectivist or multi-faceted. Among the three documents utilising the terms interchangeably, two are subjectivists and one multi-faceted.

Regardless the type of input data used, and thus of approach, the output of all composite indicators is expressed in a quantitative way, as a single numerical value. The composite indicator is calculated through aggregation of the scores of the single QWL dimensions. The majority of papers employ a weighted arithmetical mean (e.g. Arranz et al., 2018; Boccuzzo \& Gianecchini, 2015; Holman, 2013) or sum (e.g. Argentero et al., 2007; Warren \& Lyonette, 2018), often followed by normalisation (e.g. McClelland \& Holman, 2015). Only Muñoz de Bustillo et al. (2011a) adopt a geometrical mean. In a few cases all dimensions have the same weight (e.g. Crespo et al., 2017; Ventegodt et al., 2009). In other cases, a more complex aggregation approach is adopted. For example, Addabbo et al. (2007) use fuzzy sets and fuzzy rules. The majority of QWL composite indicators range between 0 and 100 ( 7 out of 19) or are expressed as percentages (6 out of 19). The remaining authors adopt other scales, which in one case (Santero-Sanchez et al., 2015) spans also negative values. Only in 3 cases some qualitative outputs are proposed in addition to a numerical index. For example, Jones et al. (2014) classify jobs into good, medium, or poor, while Heiskanen and Jokinen (2014) rank QWL level as low, medium, and high. For appreciating the wide spectrum of composite indicators, a brief description of each approach is available in Table 4 located in Appendix.

The majority of the proposed composite indicators (12 out of 19) have only been tested on one or more samples. Only five have been fully validated, while in one case (Arrranz et al., 2018) the index has been tested for robustness. One indicator is only defined, but not tested (Sojka, 2014). 


\section{Discussion}

This systematic review retrieved 19 documents proposing a composite indicator to measure QWL in European organisations. These indicators are considerably heterogeneous in terms of all the comparison factors we have taken into consideration in our analysis. This result confirms that the previous widespread statement regarding the absence of an agreed QWL composite indicator (e.g. Bäck-Wiklund et al., 2011; Green, 2006; Hurley et al., 2012; Mitlacher, 2008; Muñoz de Bustillo et al., 2011b; Santero-Sanchez et al., 2015) remains valid also by narrowing the scope of the analysis to Europe. This suggests that the objective to foster a European common understanding of QWL concept is far from being achieved. This calls for further investments on the political level by European institutions.

Our results show that in Europe there is no a unique locution for indicating QWL, and this contributes to increase the confusion about the concept and its measurement. However, it can be observed that terms such as quality of "work" or "working life" are used by those indicators interested at least in the subjective perceptions of the workers. On the contrary, "job" or "employment" are preferred by the indicators that aim to assess at least the objective features of the job. Therefore, authors proposing new QWL composite indicators are recommended to use locutions consistently with this distinction. Similarly, the name of the composite index could provide a hint on the type of approach to organisations selecting the composite indicator most suitable for their needs.

This review highlights that there is no consensus on the dimensions to include in QWL and on their names. An attempt to define a comprehensive set of QWL macro-dimensions has been made in this paper, adapting the work by Addabbo et al. (2007) and McClelland and Holman (2015). The proposed set of dimensions has proven able to accommodate the variety of aspects considered by the different authors, and aims to provide a unifying view of such debated issue. The results show that only 6 composite indicators consider all QWL dimensions. The most neglected is the "social" one. This could partially be explained by the fact that it can be assessed only through subjective inputs, which might be more difficult to collect. Ideally, future proposal of QWL composite indicators should provide a wider coverage of all QWL dimensions, trying at the same time not to increase the complexity and effort required for their implementation.

The majority of QWL composite indicators found in the literature have been developed and tested only in one European country, usually focusing on a specific population. This means that they tend to be tailored to that specific context, hindering their applicability at the European level, in other industries, or for further worker populations. In addition, they almost neglect Eastern European countries, which would particularly benefit from more attention to QWL, as suggested by their poor performance emerging from recent studies (Simões et al., 2015). This calls for additional comparative studies investigating the differences among European countries and industries, not only in terms of QWL level, but also in terms of understanding of the QWL concept.

In terms of the level of analysis, the large majority of composite indicators are assessed at the individual worker or job level, and can usually be aggregated to compare types of work, group of workers, or labour markets. The indicators focusing on the company level are only two, and specific for call centres. The higher the level of investigation, the less the data and the effort required to carry out the analysis. Indeed, it is enough to interview the managers of the call centre, not all the call centre workers, to get a measure of QWL 
performance of the entire centre. The other side of the coin is that such indicators are not able to assess all QWL dimensions, and could adopt only an objectivist approach. For instance, they completely neglect the "ergonomic" and "social" dimensions that are better investigated through individual workers' perceptions. Therefore, it appears that the individual worker or job level is the only one enabling the assessment of all QWL dimensions.

One of the main criticalities of QWL composite indicators is the resources required for data collection. For this reason, the majority of studies rely on secondary data. That becomes a necessity if the sample under investigation includes more than one country. Our review has underlined several sources of data available at national, European, and international level (such as the EWCS) useful to assess QWL and its variation across time, which could be accessed also by other researchers interested in this topic. In addition, 3 out of 4 indicators using the EWCS provide the full list of items used, although different among the studies, thus facilitating the replicability of the studies or implementation of the proposed indicator. On the contrary, only half of the studies collecting primary data offer the full set of questions/items, thus hindering their implementation by other organisations or researchers. It would be desirable that future proposals of QWL composite indicators provide all the data collection instrument details to enable their actual application.

To facilitate the use of a composite indicator, also the weighting and aggregating procedure, which are often quite complex, should be well documented. However, the possibility to assign differentiated importance weights to QWL dimensions raises the question whether the dimensions have the same relevance in every context in order to assess QWL, or if the weights should be context-specific. The uniformity of weights facilitates cross comparisons, but it might be reasonable to suppose that some dimensions may contribute to QWL more than others in different jobs or industries. Therefore, it would be important for QWL composite indicators to highlight the diverse importance of each dimension in characterising a country, an industry, or a working population. Interesting approaches for assigning a relative weight to each dimension are provided by Holman (2013), Muñoz de Bustillo et al. (2011b), and Decancq and Lugo (2013).

The surveyed QWL composite indicators are always expressed in a quantitative way, and only a few authors also propose a scale to label the scores according to qualitative categories. Although the quantitative value is more precise, qualitative categories might be an additional piece of information to facilitate comprehension and interpretation of results also by individual workers or a less specialised audience.

Unfortunately, the majority of the proposed composite indicators have not been fully validated, thus undermining their reliability. Extensive testing and proper validation of the indicators would be highly recommended.

Finally, each indicator could be complemented with recommendations about actions that can be implemented for improving the QWL level, based on the outcome of the assessment and analysis of the weakest dimensions in the specific context under investigation.

\section{Conclusions}

This paper proposes a systematic review of the composite indicators available in the scientific literature to measure QWL in European countries. Our research focuses on composite indicators and Europe, not investigating a particular industry and/or working population. Through a rigorous and reproducible methodology, we identified 19 documents and analysed them based on a set of significant factors related to QWL locutions, index name, 
geographical area, industry or population, level of analysis, dimensions, type of data, inputs, outputs, and test and/or validation. The results confirm the absence of an agreed upon composite indicator of QWL at the European level, the lack of consensus on QWL dimensions, and the proposal of different kinds of approaches (e.g. objectivist, subjectivist, or multi-faceted).

A critical comparison of the different composite indicators, highlighting their main strengths and weaknesses, is given. We also propose a set of QWL macro-dimensions able to accommodate the variety of aspects considered by the different authors with the purpose to outline a unifying framework for such open dispute.

We believe that this paper has both theoretical and practical contribution. On the theoretical side, it provides scholars and academics with an overview of the state of the art of scientific literature about composite indicators for evaluating QWL in Europe. It also points out several gaps that suggest possible directions for future research. On the practical side, the critical comparison of QWL composite indicators could support practitioners in the selection of the most suitable indicator for their specific organisation.

\section{Appendix}

See Table 4. 







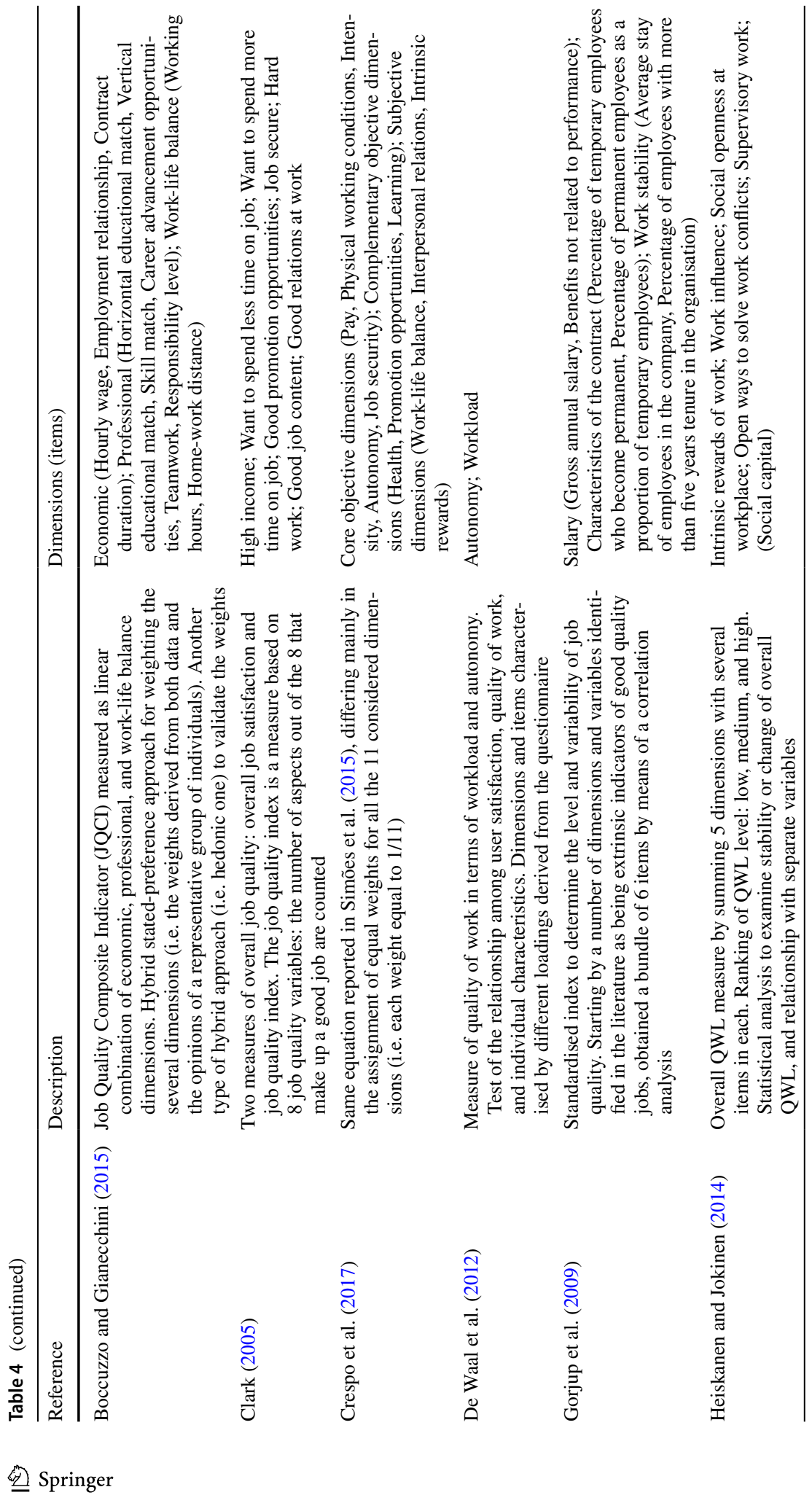




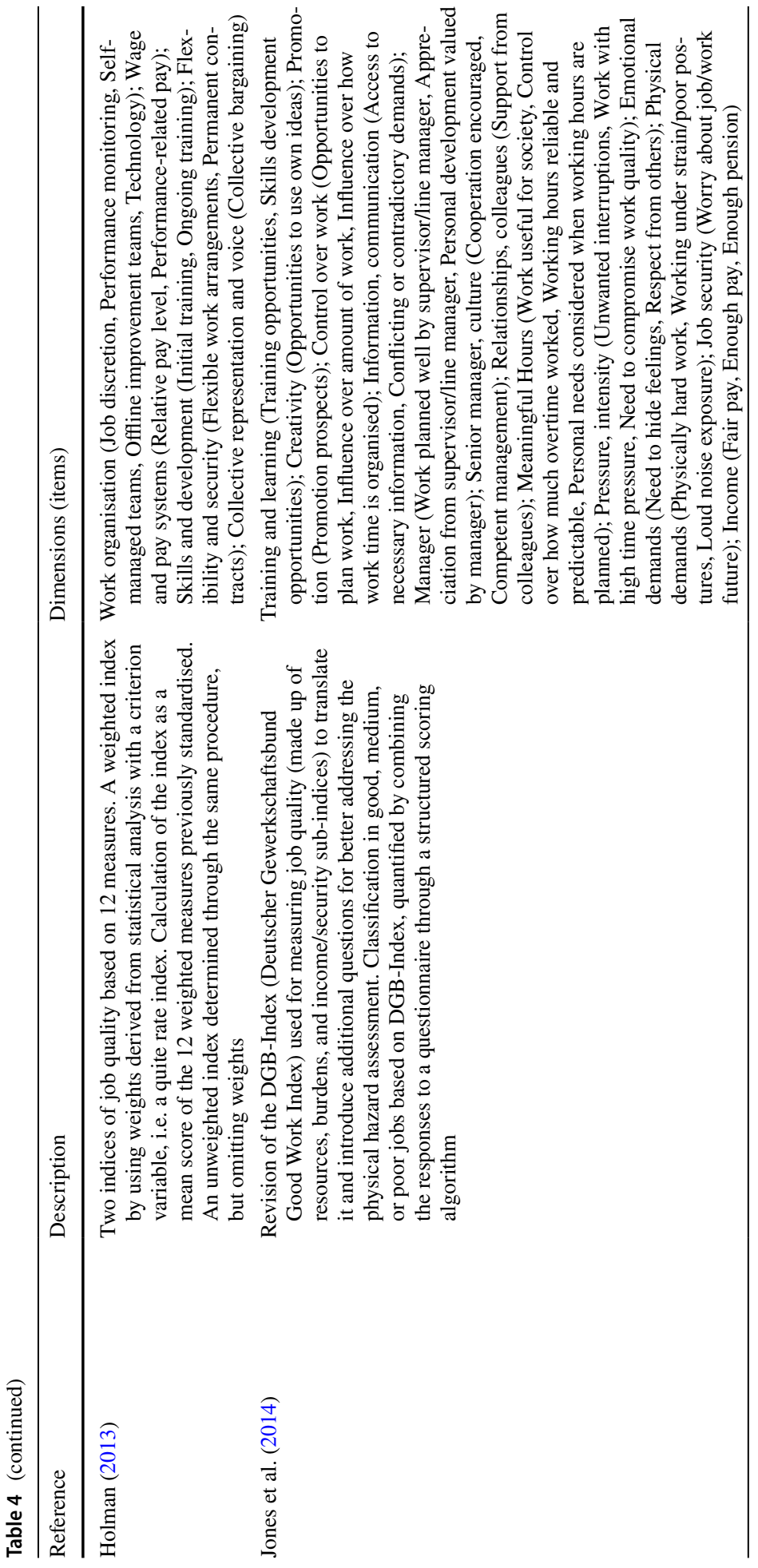




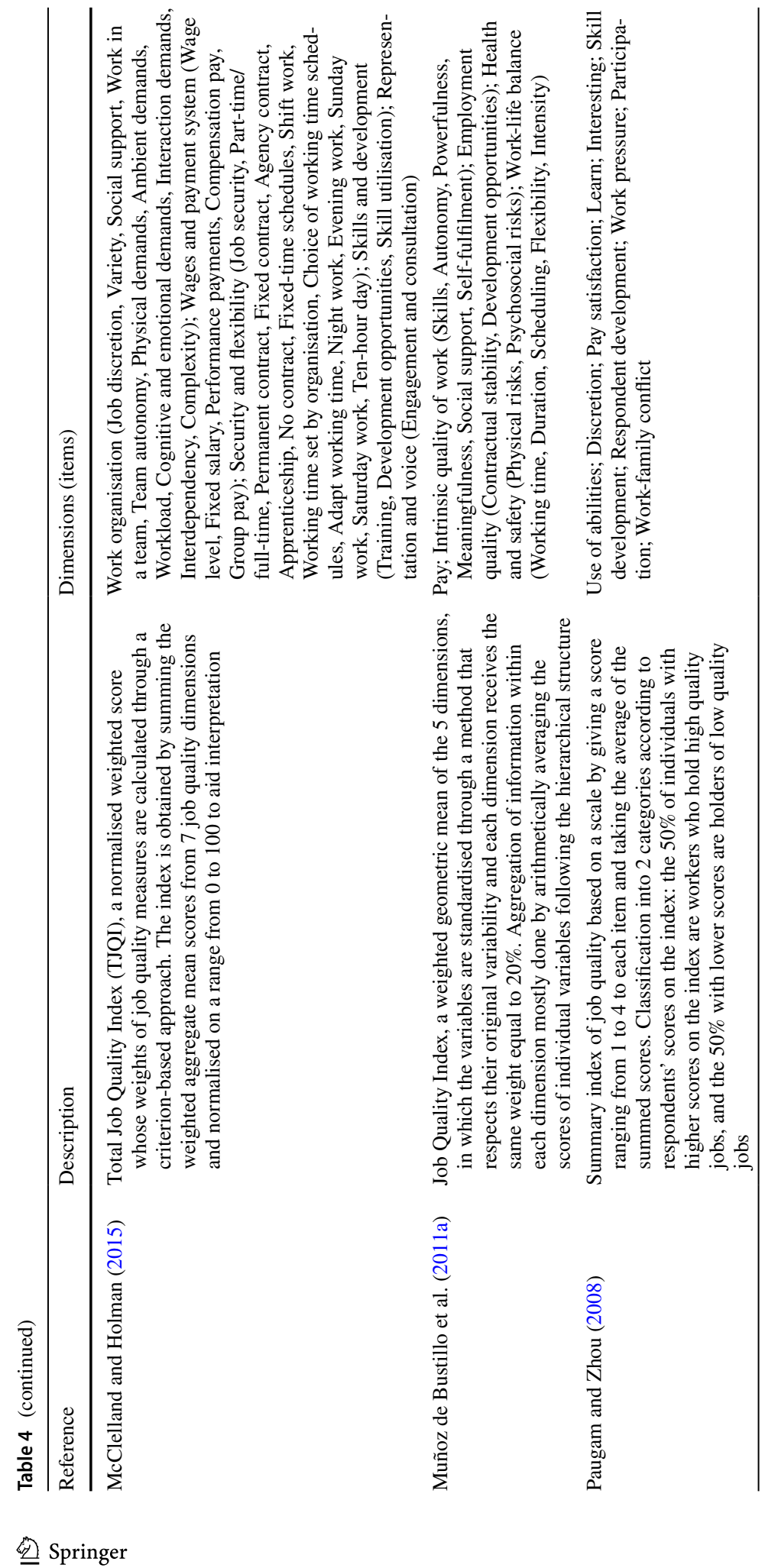




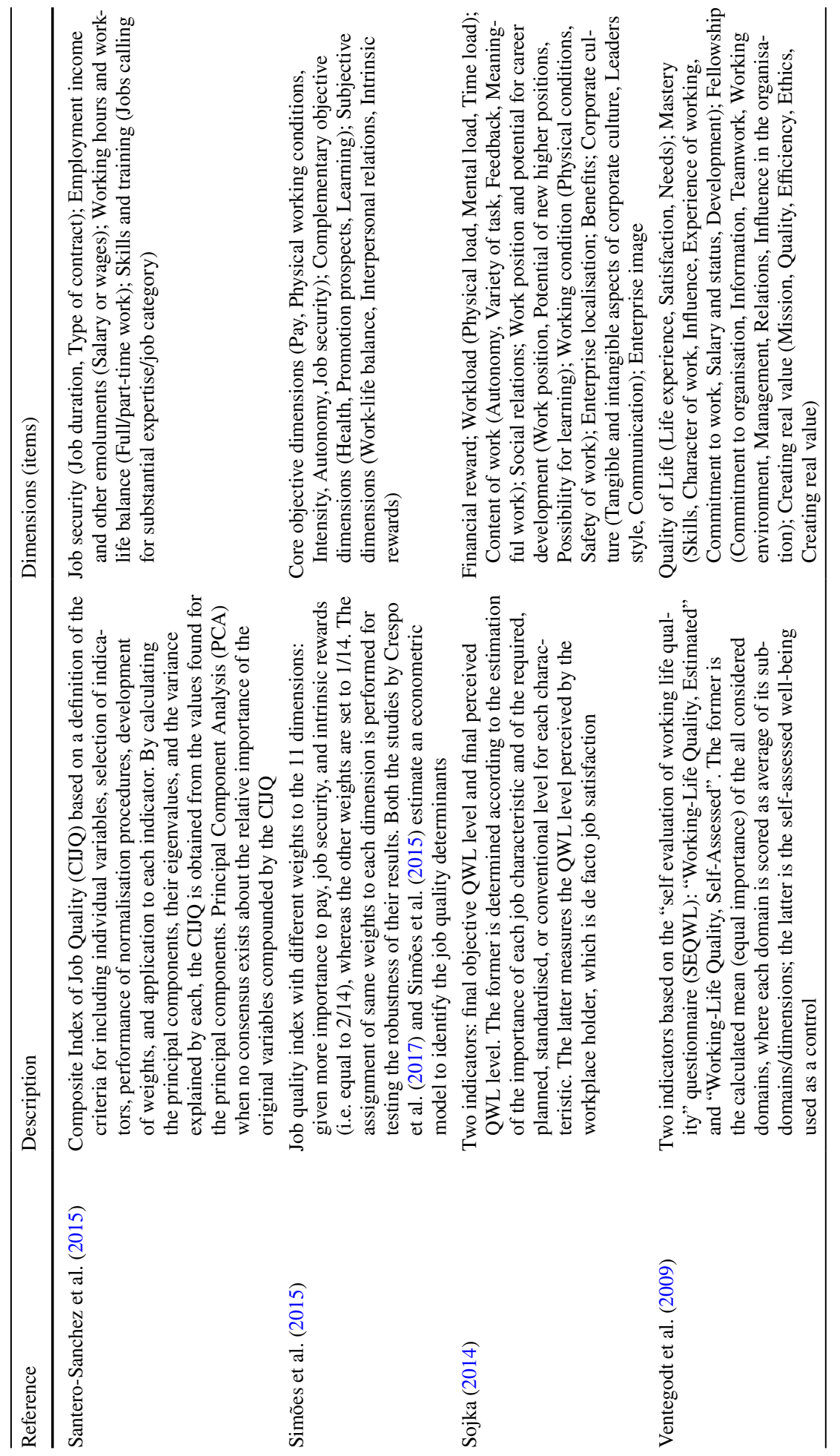




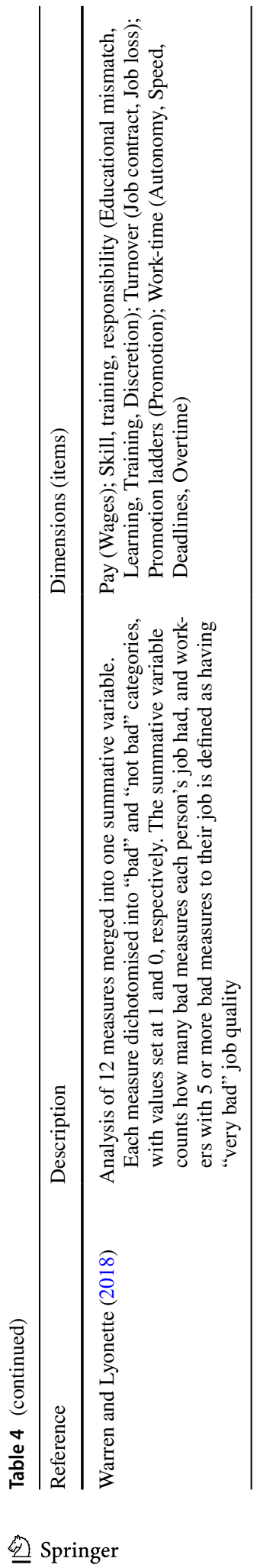


Acknowledgements This research was supported by the project "Work, Wealth, Production, Productivity" (W2P2) funded by University of Brescia.

Funding Open access funding provided by Università degli Studi di Brescia within the CRUI-CARE Agreement.

Open Access This article is licensed under a Creative Commons Attribution 4.0 International License, which permits use, sharing, adaptation, distribution and reproduction in any medium or format, as long as you give appropriate credit to the original author(s) and the source, provide a link to the Creative Commons licence, and indicate if changes were made. The images or other third party material in this article are included in the article's Creative Commons licence, unless indicated otherwise in a credit line to the material. If material is not included in the article's Creative Commons licence and your intended use is not permitted by statutory regulation or exceeds the permitted use, you will need to obtain permission directly from the copyright holder. To view a copy of this licence, visit http://creativecommons.org/licenses/by/4.0/.

\section{References}

Addabbo, T., Facchinetti, G., Mastroleo, G., \& Solinas, G. (2007). A fuzzy way to measure quality of work in a multidimensional perspective. In J. Pejaś \& K. Saeed (Eds.), Advances in Information Processing and Protection. (pp. 13-23). Springer.

Argentero, P., Miglioretti, M., \& Angilletta, C. (2007). Quality of work life in a cohort of italian health workers. Giornale Italiano di Medicina del Lavoro ed Ergonomia, 29(1), A50-A54

Arranz, J. M., García-Serrano, C., \& Hernanz, V. (2018). Employment quality: Are there differences by types of contract? Social Indicators Research, 137, 203-230

Bäck-Wiklund, M., van der Lippe, T., den Dulk, L., \& Doorne-Huiskes, A. (Eds.). (2011). Quality of Life and Work in Europe. Theory, Practice and Policy. Palgrave Macmillan.

Bang, H., \& Lee, S. (2006). The definition of 'Good Job' and determinant. The Korean Sociology, 1, 93-126

Barroso, M. M. (2018). Quality of work research: A methodological review. Portuguese Journal of Social Science, 17(1), 89-103

Boccuzzo, G., \& Gianecchini, M. (2015). Measuring young graduates' job quality through a composite indicator. Social Indicators Research, 122, 453-478

Boisvert, M. (1977). La qualité de vie au travail. École des Hautes Études Commerciales.

Bothfeld, S., \& Leschke, J. (2012). 'More and better jobs': Is quality of work still an issue-and was it ever? Transfer, 18(3), 337-353

Briner, R. B., \& Denyer, D. (2012). Systematic review and evidence synthesis as a practice and scholarship tool. In D. M. Rousseau (Ed.), Handbook of Evidence-Based Management: Companies, Classrooms and Research. (pp. 112-129). Oxford University Press.

Burchell, B., Sehnbruch, K., Piasna, A., \& Agloni, N. (2014). The quality of employment and decent work: Definitions, methodologies, and ongoing debates. Cambridge Journal of Economics, 38(2), 459-477

Burgess, J., \& Connell, J. (2008). Introduction to special issue-HRM and job quality: An overview. The International Journal of Human Resource Management, 19(3), 407-418

Carpita, M., \& Golia, S. (2012). Measuring the quality of work: The case of the Italian social cooperatives. Quality and Quantity, 46(6), 1659-1685

Clark, A. (2005). What makes a good job? evidence from OECD countries. In S. Bazen, C. Lucifora, \& W. Salverda (Eds.), Job Quality and Employer Behaviour. (pp. 11-30). Palgrave Macmillan.

Commission, E. (2001). Communication from the Commission to the Council, the European Parliament, the Economic and Social Committee and the Committee of the Regions-Employment and social policies: a framework for investing in quality. Communication of the European Communities.

Crespo, N., Simoes, N., \& Pinto, J. C. (2017). Determinant factors of job quality in Europe. Argumenta Oeconomica, 1(38), 15-40

Dahl, S. A., Nesheim, T., \& Olsen, K. M. (2009). Quality of work - concept and measurement. Working Paper. Edinburgh: University of Edinburgh.

De Waal, B. M. E., Breman, P., \& Batenburg., R. . (2012). Do individual characteristics matter? The quality of work during the implementation of a workflow management system in a Dutch social insurance company. International Journal of Business Information Systems, 11(1), 1-21

Decancq, K., \& Lugo, M. A. (2013). Weights in multidimensional indices of wellbeing: An overview. Econometric Reviews, 32(1), 7-34 
Denyer, D., \& Tranfield, D. (2009). Producing a systematic review. In D. A. Buchanan \& A. Bryman (Eds.), The Sage Handbook of Organizational Research Methods. (pp. 671-689). Sage Publications.

Denyer, D., Tranfield, D., \& van Aken, J. E. (2008). Developing design propositions through research synthesis. Organization Studies, 29(03), 393-413

Díaz-Chao, Á., Ficapal-Cusí, P., \& Torrent-Sellens, J. (2016). Economic crisis and job quality in Spain: A multi-dimensional and micro-data empirical approach. Social Indicators Research, 125, 613-633

Díaz-Chao, Á., Ficapal-Cusí, P., \& Torrent-Sellens, J. (2017). Did small and medium enterprises maintain better jobs during the early years of the recession? Job quality multidimensional evidence from Spain. European Management Journal, 35, 396-413

Diaz-Serrano, L., \& Vieira, J. (2005). Low Pay, Higher Pay and Job Satisfaction within the European Union: Empirical Evidence from Fourteen Countries. Bonn: Institute for the Study of Labour (IZA).

Dolan, S. L., García, S., Cabezas, C., \& Tzafrir, S. S. (2008). Predictors of "quality of work" and "poor health" among primary health-care personnel in Catalonia: Evidence based on cross-sectional, retrospective and longitudinal design. International Journal of Health Care Quality Assurance, 21(2), 203-218

Efraty, D., \& Sirgy, M. J. (1990). The effects of quality of working life (QWL) on employee behavioral responses. Social Indicators Research, 22, 31-47

European Foundation for the Improvement of Living and Working Conditions (Eurofound) (2012). Trends in job quality in Europe. Publications Office of the European Union.

European Foundation for the Improvement of Living and Working Conditions (Eurofound) (2017). Sixth European working conditions survey-overview report (2017 update). Publications Office of the European Union.

Ferraro, T., dos Santos, N. R., Pais, L., \& Moreira, J. M. (2017). Decent work and work motivation in lawyers: An empirical research. Revista Psicologia: Organizações e Trabalho, 17(4), 192-200

Ferraro, T., Moreira, J. M., dos Santos, N. R., Pais, L., \& Sedmak, C. (2018). Decent work, work motivation and psychological capital: An empirical research. Work, 60, 339-354

Ficapal-Cusí, P., Díaz-Chao, A., Sainz-Ibáñez, M., \& Torrent-Sellens, J. (2018). Gender inequalities in job quality during the recession. Employee Relations, 40(1), 2-22

Gorjup, M. T., Valverde, M., \& Ryan, G. (2009). In search of job quality in call centers. Personnel Review, 38(3), 253-269

Greco, S., Ishizaka, A., Tasiou, M., \& Torrisi, G. (2019). On the methodological framework of composite indices: A review of the issues of weighting, aggregation, and robustness. Social Indicators Research, 141(1), 61-94

Green, F. (2006). Demanding work: The paradox of job quality in the affluent economy. Princeton University Press.

Guglielmi, O., Díaz-Piedra, C., Saez-Roca, G., Lopez-Ortiz, S., \& Buela-Casal, G. (2010). Seriousness effects of obstructive sleep apnoea syndrome in burnout, stress and job satisfaction. Journal of Sleep Research, 19(s2), 374

Heiskanen, T., \& Jokinen, E. (2014). Stability and change of the quality of working life in restructuring municipalities. Social Indicators Research, 118, 579-599

Higgins, J. P. T., \& Green, S. (2008). Cochrane handbook for systematic reviews of interventions. Wiley.

Holman, D. (2013). An explanation of cross-national variation in call centre job quality using institutional theory. Work, Employment and Society, 27(1), 21-38

Hurley, J., Fernández-Macías, E., \& Muñoz de Bustillo, R. (2012). Assessing recent employment shifts in europe using a multidimensional job quality indicator. In E. Fernández-Macías, J. Hurley, \& D. Storrie (Eds.), Transformation of the Employment Structure in the EU and USA, 1995-2007. (pp. 147-179). Palgrave Macmillan.

International Labour Organization (ILO) (1999). Decent work. Report, Director General. Geneva: International Labour Conference, 87th Meeting.

Jones, W., Haslam, R., \& Haslam, C. (2014). Measuring job quality: A study with bus drivers. Applied Ergonomics, 45(6), 1641-1648

Jones, W., Haslam, R., \& Haslam, C. (2017). What is a 'good' job? Modelling job quality for blue collar workers. Ergonomics, 60(1), 138-149

Lawler, E. E. (1975). Measuring the psychological quality of working life: The why and how of it. In L. E. Davis \& A. B. Cherns (Eds.), The Quality of Working Life. (Vol. 1, pp. 123-133). Free Press.

Leontaridi, R. M., Sloane, P. J., \& Jones, R. J. (2005). Are low paid jobs of low quality? Some British evidence. International Journal of Economics Research, 2(2), 147-172

Leschke, J., \& Watt, A. (2014). Challenges in constructing a multi-dimensional european job quality index. Social Indicators Research, 118, 1-31 
Martel, J. P., \& Dupuis, G. (2006). Quality of work life: Theoretical and methodological problems, and presentation of a new model and measuring instrument. Social Indicators Research, 77(2), 333-368

McClelland, C., \& Holman, D. (2015). Examining the quality of jobs amongst vulnerable groups of workers in Europe. In U. Holtgrewe, V. Kirov, \& M. Ramioul (Eds.), Hard work in new jobs: The quality of work and life in European growth sectors. (pp. 49-69). Palgrave Macmillan.

Mitlacher, L. W. (2008). Job quality and temporary agency work: Challenges for human resource management in triangular employment relations in Germany. The International Journal of Human Resource Management, 19(3), 446-460

Moher, D., Liberati, A., Tetzlaff, J., Altman, D. G., \& The PRISMA Group. (2009). Preferred reporting items for systematic reviews and meta-analyses: The PRISMA statement. PLOS Medicine, 6(7), e1000097

Morton, H. C. (1977). A look at factors affecting the quality of working life. Monthly Labor Review, 100(10), 64-65

Muñoz de Bustillo, R., Fernandez-Macias, E., Antón, J. I., \& Esteve, F. (2009). Indicators of job quality in the European Union. IP/A/EMPL/ST/2008-09. PE 429.972. Brussels: European Parliament.

Muñoz de Bustillo, R., Fernández-Macías, E., Antón, J. I., \& Esteve, F. (2011a). Measuring More Than Money: The Social Economics of Job Quality. Edward Elgar Publishing.

Muñoz de Bustillo, R., Fernández-Macías, E., Esteve, F., \& Antón, J. I. (2011b). E pluribus unum? A critical survey of job quality indicators. Socio-Economic Review, 9, 447-475

European Commission (2001b). Employment in Europe 2001. Recent Trends and Prospects. Luxembourg: Office for Official Publications of the European Communities.

Organisation for Economic Co-operation and Development (OECD), \& Joint Research Centre (JRC) European Commission. (2008). Handbook on Constructing Composite Indicators - Methodology and User Guide. OECD Publications.

Paugam, S., \& Zhou, Y. (2008). Job insecurity. In D. Gallie (Ed.), Employment Regimes and the Quality of Work. (pp. 179-204). Oxford University Press.

Pena-Casas, R. (2009). More and better jobs: conceptual framework and monitoring indicators of quality of work and employment in the EU policy arena. Working Papers on the Reconciliation of Work and Welfare in Europe, REC-WP 06/2009. Edinburgh: University of Edinburgh, Publication and Dissemination Centre.

Phan, G. T., \& Vo, T. Q. (2016). A literature review on quality of working life: A case of healthcare workers. Journal of Applied Pharmaceutical Science, 6(07), 193-200

Pusch, T., \& Rehm, M. (2017). Positive effects of the german minimum wage on job quality and employee job satisfaction. Wirtschaftsdienst, 97, 409-414 (in German).

Saltelli, A. (2006). Composite indicators between analysis and advocacy. Social Indicators Research, $81(1), 65-77$

Santero-Sanchez, R., Segovia-Pérez, M., Castro-Nuñez, B., Figueroa-Domecq, C., \& Talón-Ballestero, P. (2015). Gender differences in the hospitality industry: A Job quality index. Tourism Management, 51, 234-246

Schnalzenberger, M., Schneeweis, N., Winter-Ebmer, R., \& Zweimüller, M. (2014). Job quality and employment of older people in Europe. Labour, 28(2), 141-162

Schokkaert, E., Van Ootegem, L., \& Verhofstadt, E. (2011). Preferences and subjective satisfaction: Measuring well-being on the job for policy evaluation. CESifo Economic Studies, 57(4), 683-714

Secapramana, V. H., \& Nugroho, E. (2017). Quality of work life program as a humanistic perspective on HRM. Advances in Intelligent Systems Research, 131, 28-33

Simms, M. (2017). Unions and job quality in the UK: Extending interest representation within regulation institutions. Work and Occupations, 44(1), 47-67

Simões, N., Crespo, N., \& Pinto, J. C. (2015). Determinants of job quality-evidence for European country groups. Acta Oeconomica, 65(2), 299-323

Sirgy, M. J., Efraty, D., Siegel, P., \& Lee, D. J. (2001). A new measure of quality of work life (QWL) based on need satisfaction and spillover theories. Social Indicators Research, 55, 241-302

Smith, M., Burchell, B., Fagan, C., \& O’Brien, C. (2008). Job quality in Europe. Industrial Relations Journal, 39(6), 586-603

Sojka, L. (2014). Specification of the quality of work life characteristics in the slovak economic environment. Sociológia, 46(3), 283-299 
Spector, P. E. (1997). Job Satisfaction: Application, Assessment, Causes, and Consequences. SAGE Publications.

Stefana, E., Marciano, F., Cocca, P., \& Alberti, M. (2015). Predictive models to assess Oxygen Deficiency Hazard (ODH): A systematic review. Safety Science, 75, 1-14

Steffgen, G., Kohl, D., Reese, G., Happ, C., \& Sischka, P. (2015). Quality of Work: Validation of a new instrument in three languages. International Journal of Environmental Research and Public Health, $12,14988-15006$

Stepanova, E., Sotnikova, Y., \& Nazarov, N. (2015). Quality of working life as a strategic direction of domestic enterprises' activity. Economic Annals-XXI, 7-8(1), 106-108

Sutherland, J. (2016). Job quality in Scotland. . Scottish Affairs, 25(3), 337-371

Šverko, B., \& Galić, Z. (2014). The perceived quality of working life in Croatia and the European Union. Društvena istraživanja: časopis za opća društvena pitanja, 23(4), 557-575

Tangian, A. S. (2005). A composite indicator of working conditions in the EU-15 for policy monitoring and analytical purposes. WSI-Diskussionspapier, No. 135. Düsseldorf: Hans-Böckler-Stiftung, Wirtschafts- und Sozialwissenschaftliches Institut (WSI).

Tranfield, D., Denyer, D., \& Smart, P. (2003). Towards a methodology for developing evidence-informed management knowledge by means of systematic review. British Journal of Management, 14, 207-222

Ventegodt, S., Andersen, N. J., \& Merrick, J. (2009). Working life quality with the SEQWL questionnaire. In S. Ventegodt \& J. Merrick (Eds.), Health and Happiness from Meaningful Work: Research in Quality of Working Life. (pp. 125-154). Nova Science Publishers Inc.

Vinopal, J. (2012). The discussion of subjective quality of working life indicators. Sociológia-Slovak Sociological Review, 44(3), 385-401

Warren, T., \& Lyonette, C. (2018). Good, bad and very bad part-time jobs for women? Re-examining the importance of occupational class for job quality since the 'Great Recession' in Britain. Work, Employment and Society, 32(4), 747-767

Weinkopf, C. (2014). Women's employment in Germany: Robust in crisis but vulnerable in job quality. Revue de l'OFCE, 133(2), 189-214

Publisher's Note Springer Nature remains neutral with regard to jurisdictional claims in published maps and institutional affiliations.

\section{Authors and Affiliations}

\section{Elena Stefana ${ }^{1}$ (D) Filippo Marciano ${ }^{1}$ (D) - Diana Rossi ${ }^{1}$ (D) Paola Cocca ${ }^{1}$ (D) . Giuseppe Tomasoni ${ }^{1}$}

Filippo Marciano

filippo.marciano@unibs.it

Diana Rossi

diana.rossi@unibs.it

Paola Cocca

paola.cocca@unibs.it

Giuseppe Tomasoni

giuseppe.tomasoni@unibs.it

1 Department of Mechanical and Industrial Engineering, University of Brescia, via Branze 38, 25123 Brescia, Italy 